\title{
Surfaces of Silicates in Contact with Alkaline Aqueous Solutions II
}

\author{
C. A. M. SISKENS, H. N. STEIN, ${ }^{1}$ and J. M. STEVELS \\ Laboratories of Inorganic and General Chemistry, Eindhoven University of Technology, \\ Eindhoven, The Netherlands
}

Received September 13, 1974; accepted April 30, 1975

\begin{abstract}
Adsorption measurements on $\alpha-\mathrm{CaSiO}_{3}$ and $\mathrm{CaAl}_{2} \mathrm{Si}_{2} \mathrm{O}_{8}$ indicate that $\mathrm{Ca}^{2+}$ and $\mathrm{OH}^{-}$adsorption stimulate each other. This is ascribed to $\mathrm{Ca}^{2+}$ adsorption sites being surrounded preferentially by $\mathrm{OH}^{-}$adsorption sites, and $\mathrm{OH}^{-}$sites being surrounded by $\mathrm{Ca}^{2+}$ sites. Part of the negative charge present on the $\mathrm{CaAl}_{2} \mathrm{Si}_{2} \mathrm{O}_{8}$ surfaces derives from desorption of positive network fragments $\left(\mathrm{Al}^{3+}, \mathrm{AlO}^{+}\right)$.
\end{abstract}

\section{INTRODUCTION}

In previous papers $(1,2)$, electrokinetic data have been reported for some calcium (alumino) silicates showing that the surfaces of these materials in contact with aqueous solutions did not show, under the conditions investigated $(0.01 \mathrm{~N} \mathrm{NaOH}$, contact time $\leqslant 3 \mathrm{hr})$, surface hydration to an extent that would mask the difference in structure between a vitreous and a crystalline material of similar composition.

The present investigation intends to provide insight into the charging processes for two of the compounds $\left(\alpha-\mathrm{CaSiO}_{3}\right.$ and $\left.\mathrm{CaAl}_{2} \mathrm{Si}_{2} \mathrm{O}_{8}\right)$ whose electrokinetic properties have been described previously.

\section{EXPERIMENTAL}

Materials used were as described previously (2). The surface area of the $\alpha-\mathrm{CaSiO}_{3}$ sample as determined by means of an Areameter (Ströhlein) was $0.49 \mathrm{~m}^{2} \mathrm{~g}^{-1}$ and that of the $\mathrm{CaAl}_{2} \mathrm{Si}_{2} \mathrm{O}_{8}$ sample was $0.40 \mathrm{~m}^{2} \mathrm{~g}^{-1}$. The $\mathrm{CaCl}_{2}$ solution containing ${ }^{45} \mathrm{Ca}$ was obtained from the Radiochemical Centre, Amersham, Great Britain. The total $\mathrm{Ca}^{2+}$ was $1.0 \times 10^{-3} M$ and its specific activity was $0.82 \mathrm{mCi} \mathrm{ml}^{-1}$.

${ }^{1}$ To whom correspondence should be addressed.
The ethanol used was absolute (Merck, pro analysi).

\section{METHODS}

$\mathrm{OH}^{-}$titrations were performed to a $\mathrm{pH}$ of 5 . $\mathrm{Ca}^{2+}$ titrations were as described previously (2). ${ }^{45} \mathrm{Ca}$ was determined by liquid scintillation counting (3), using a Packard Tri-Carb Liquid Scintillation Spectrometer, Model 3320, and a Packard No. 6002173 emulsion ("Instagel"). Channel adjustment and amplification were chosen to give the highest efficiency and signal-to-background ratio, allowance being made for quenching by counting in two different channels. The ratio of the counts obtained in the two channels could be used, after calibration, as a measure for the counting efficiency.

The $\mathrm{Cl}^{-}$was determined by potentiometric titration with $0.01 \mathrm{M} \mathrm{AgNO}_{3}$ (electrodes were a silver wire and a calomel electrode connected through a $\mathrm{KNO}_{3}$ salt bridge with the titration vessel and the $\mathrm{mV}$ meter used was the Orion digital $\mathrm{pH}$ measuring unit, Model 701). The potentials were plotted against the volume of the $\mathrm{AgNO}_{3}$ solution as described by Gran (4).

$\mathrm{Al}^{3+}$ was determined by means of a Perkin Elmer Atomic Absorption Spectrophotometer, 
model $300(5,6)$, connected to a Goerz Servogor $\mathrm{RE} 511$ recorder.

\section{Ad and Desorption Measurements}

(a) Nontracer experiments. A sample containing accurately weighed amounts of solid $(5 \mathrm{~g})$ and liquid $(35 \mathrm{ml})$ was magnetically stirred in a 75-ml stoppered polyethylene vessel. The liquid contained $0.01 N \mathrm{NaOH}$ and varying amounts of $\mathrm{CaCl}_{2}$. Magnetic stirring was adjusted to prevent sedimentation. After $150 \mathrm{~min}$ of $S$ (olid) $/ L$ (iquid) contact, separation of solid and liquid was effected by centrifugation ( $45 \mathrm{~min}, 20000 \mathrm{rpm}$ ). The upper layer of the supernatant was discarded (because some very small particles appeared to float at the air/solution interface), the rest of the supernatant was siphoned off and analyzed immediately (maximum time between separation and final titration was $25 \mathrm{~min}$ ). A blank run showed that $\mathrm{CO}_{2}$ influence was absent.

(b) Tracer experiments. A minute amount of tracer solution containing approximately 2 $\mu \mathrm{Ci}$ was added to the liquid; the latter's radioactivity was determined before and after contact with the solid. $S / L$ contact times varied from $15 \mathrm{~min}$ to $24 \mathrm{hr}$. Solid and liquid were separated by centrifugation ( $5 \mathrm{~min}, 4000 \mathrm{rpm}$ ), and the liquid contained in the pores of the sediment was displaced by adding $30 \mathrm{ml}$ of ethanol, stirring magnetically, and centrifuging. The remaining solid was dried ( $15 \mathrm{hr}$ at $70^{\circ} \mathrm{C}$ ) and weighed and its radioactivity was determined.

Desorption of ${ }^{45} \mathrm{Ca}$ was determined by stirring the solid thus obtained in $35 \mathrm{ml}$ of the liquid with a composition similar to that added first, but not containing ${ }^{45} \mathrm{Ca}$, for $30 \mathrm{~min}$.

\section{RESULTS}

(a) $\alpha-\mathrm{CaSiO}_{3}$

In Fig. 1, the charges brought to the surface per unit area by adsorption of $\mathrm{Ca}^{2+}$ and $\mathrm{OH}^{-}$ from $0.01 \mathrm{~N} \mathrm{NaOH}$ solutions of varying $\mathrm{CaCl}_{2}$ concentration are compared with the total charge behind the electrokinetic slipping plane.
The latter was calculated from the relation (7):

$$
\begin{aligned}
\sigma_{\mathrm{s} 1 \mathrm{pl}} & =-\epsilon_{r} \epsilon_{o}\left(\frac{d \phi}{d x}\right)_{\mathrm{sl} \mathrm{p} 1} \\
& =-\left\{2 k T \epsilon_{r} \epsilon_{o} \sum_{i} N_{i \infty}\left[\exp \left(-\frac{z_{i} e_{o} \zeta}{k T}\right)-1\right]\right\}^{\frac{1}{2}}
\end{aligned}
$$

where $\sigma$ is expressed in $\mathrm{C} \mathrm{m}^{-2}$ if MKSA units are used throughout $\left(\epsilon_{r}=\right.$ dielectric constant of the medium; $\epsilon_{o}=$ permittivity of free space; $N_{\text {ico }}=$ bulk concentration of ions of type $i$; $z_{i}=$ valency including sign $;$ and $e_{0}=$ charge of the proton).

The charge brought to the surface by ad or desorption of $\mathrm{Ca}^{2+}$ has been calculated from:

$$
\sigma_{\mathrm{Ca}^{2+}}=-2 F(V \Delta c / m s)
$$

where $\Delta c=$ difference in $\left[\mathrm{Ca}^{2+}\right]$ before and after $S / L$ contact; $V=$ volume of the liquid; $m=$ mass of solid present; $s=$ surface area of solid; $F=$ Faraday constant.

A similar formula was employed for $\sigma_{\mathrm{OH}^{-}}$, the surface charge due to ad or desorption of $\mathrm{OH}^{-}$. It appears from the method of determination that dissociation of surface $\mathrm{SiOH}$ groups is indistinguishable from $\mathrm{OH}^{-}$adsorption. Thus, the term " $\mathrm{OH}^{-}$adsorption" will include in the following $\mathrm{SiOH}$ dissociation, whereas $\mathrm{OH}^{-}$desorption includes the reverse process.

The quantities $\sigma_{\mathrm{Ca}^{2+}}$ and $\sigma_{\mathrm{OH}}{ }^{-}$are independent of any assumption about the number of sites per unit area, but they are based on the assumption that the surface area as determined by Areameter (essentially a BET type measurement) is the surface area which is significant for processes at the $S / L$ interface. For silicates, some experimental basis for this assumption is available $(8,9)$.

The net surface charge within the electrokinetic slipping plane is seen to be $1-2 \%$ of $\sigma_{\mathrm{Ca}^{2+}}$. The latter is compensated almost exclusively by $\mathrm{OH}^{-}$adsorption, not by $\mathrm{Cl}^{-}$ adsorption even when $\mathrm{Cl}^{-}$predominates in the bulk solution (as is the case in $3.10^{-2} M \mathrm{CaCl}_{2}$ solution). Only at lower $\mathrm{CaCl}_{2}$ concentrations, 


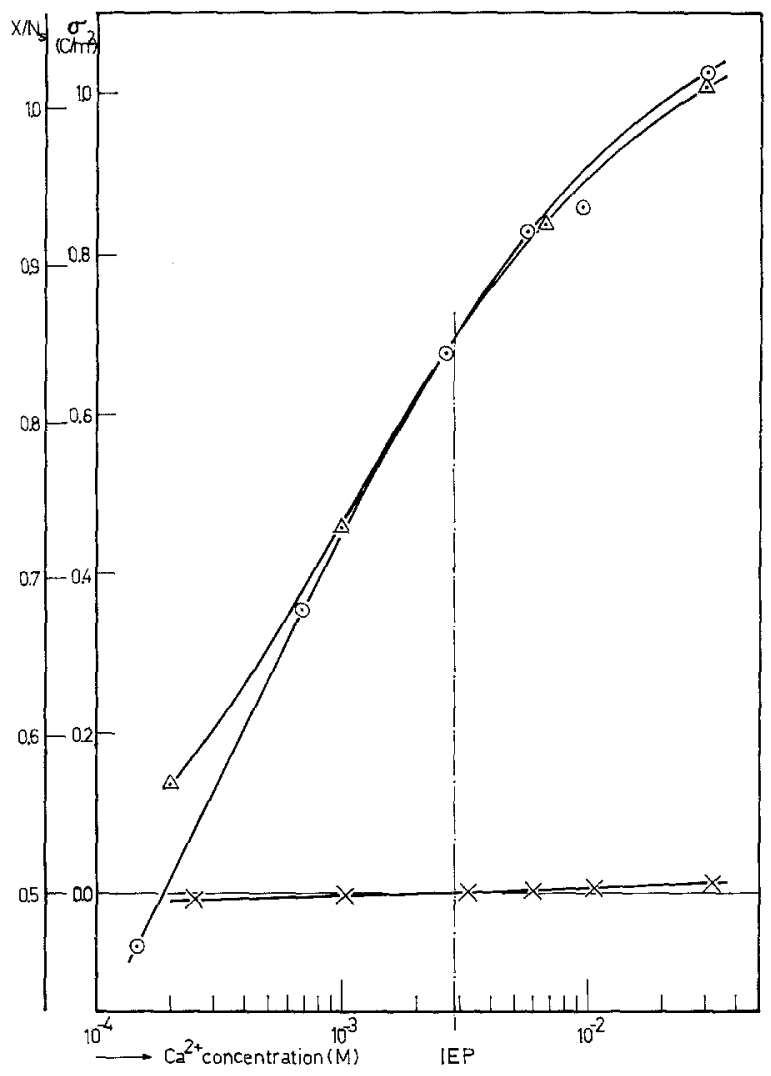

Frg. 1. Charges on $\alpha-\mathrm{CaSiO}_{3} . \odot, \sigma_{\mathrm{Ca}}$ (the charge brought to the surface by ad or desorption of $\mathrm{Ca}^{2+}$ per unit area); $\Delta,-\sigma_{\mathrm{OH}} ; X, \sigma_{\mathrm{sl}} \mathrm{pl}$ (the net charge between the electrokinetic slipping plane and the bulk solid); $X / N_{s}$, overall fraction of $\mathrm{Ca}^{2+}$ surface sites occupied.

a distinct discrepancy exists between $\sigma_{\mathrm{Ca}^{2+}}$ and $\sigma_{\mathrm{OH}^{-}}$and the charge within the electrokinetic slipping plane; this is ascribed to adsorption of $\mathrm{Na}^{+}$ions into the region between solid and electrokinetic slipping plane rather than to desorption of part of the silicate anions, because the latter process would expose $\mathrm{Ca}^{2+}$ ions, which are easily desorbed from the solid in the concentration region concerned. Thus, desorption of part of the silicate anions would just create a new surface.

For comparison of $\mathrm{Ca}^{2+}$ adsorption as determined from titration and from tracer experiments, see Table I.

The difference $K_{a}{ }^{*}-K_{a}$ is the amount of $\mathrm{Ca}^{2+}$ desorbed during the adsorption step. At lower $\mathrm{CaCl}_{2}$ concentrations, it corresponds to $30-60 \%$ of the $\mathrm{Ca}^{2+}$ ions originally present in the outermost layer (estimated on the assumption of random passage of the surface through crystal unit cells, leading to an area per adsorption site equal to (volume per $\mathrm{Ca}^{2+}$ in the solid) ${ }^{\frac{3}{3}}$ and an average degree of occupation $=\frac{1}{2}$ of a site in the original surface). This means that in the original surface not all ions occupy an optimal site and that net transport to more favorable sites is made easier in the presence of an electrolyte solution, as long as the latter does not contain large concentrations of $\mathrm{CaCl}_{2}$. At higher $\mathrm{CaCl}_{2}$ concentrations, $K_{a}{ }^{*}-K_{a}$ becomes small (even negative at $[\mathrm{CaCl}]=3$. $10^{-2} M$, which is ascribed to experimental error). In these solutions $\mathrm{Ca}^{2+}$ ions adsorbed quickly after solid/liquid contact, appear to block the movement of other $\mathrm{Ca}^{2+}$ ions from the solid to the solution. 
TABLE I

Tracer Adosorption of $\mathrm{Ca}^{2+}$ ON a- $\mathrm{CaSiO}_{3}$ IN $0.01 N \mathrm{NaOH}^{a}$

\begin{tabular}{|c|c|c|}
\hline $\begin{array}{c}{\left[\mathrm{CaCl}_{2}\right]} \\
\text { after } \\
\text { adsorption } \\
\left(10^{-3} M\right)\end{array}$ & $K_{a}\left(\mu\right.$ mole $\left.\mathrm{m}^{-2}\right)$ & $K_{a}{ }^{*}$ \\
\hline 0.148 & -0.34 & 4.3 \\
\hline 0.695 & 1.84 & 6.0 \\
\hline 2.611 & 3.52 & 7.4 \\
\hline 5.607 & 4.31 & 7.4 \\
\hline 9.459 & 4.46 & 6.0 \\
\hline 30.241 & 5.32 & 4.0 \\
\hline
\end{tabular}

a Adsorption time: $150 \mathrm{~min}$.

$K_{a}=$ net amount of $\mathrm{Ca}^{2+}$ adsorbed during the adsorption process, as determined by titration.

$K_{a}{ }^{*}=$ total amount of $\mathrm{Ca}^{2+}$ adsorption during the adsorption process, as determined by tracer experiments.

\section{(b) $\mathrm{CaAl}_{2} \mathrm{Si}_{2} \mathrm{O}_{8}$ (Anorthite)}

Fig. 2 shows data for anorthite similar to those described by Fig. 1 for $\alpha$-CaSiO 3 . Its significant features are:

1. Both $\mathrm{Ca}^{2+}$ and $\mathrm{OH}^{-}$adsorption on anorthite, as function of $\log \left[\mathrm{CaCl}_{2}\right]$, show an increased slope at high $\left[\mathrm{CaCl}_{2}\right]$, the transition being for $\mathrm{Ca}^{2+}$ near $5.5 \times 10^{-3} M \mathrm{CaCl}_{2}$. At this concentration, $33.5 \mathrm{Ca}^{2+}$ ions are present on $10 \mathrm{~nm}^{2}$ of the surface. At higher $\left[\mathrm{CaCl}_{2}\right]$, the number of $\mathrm{Ca}^{2+}$ ions present surpasses the number of $\mathrm{Ca}^{2+}$-sites (estimated to be 33 on 10 $\mathrm{nm}^{2}$ ). Under these conditions, $\mathrm{Ca}^{2+}$ "adsorption" apparently envolves the formation of hydrates either on the $S / L$ interface, or totally outside of the solid.

2. $\mathrm{Ca}^{2+}$ and $\mathrm{OH}^{-}$adsorption cannot account for the total charge behind the electrokinetic slipping plane; over the whole concentration range investigated there must be additional anions in the region near the solid. At positive surface charges, adsorption of $\mathrm{Cl}^{-}$ could be held responsible; however, this should be especially pronounced at high $\left[\mathrm{CaCl}_{2}\right]$ where the $\left[\mathrm{Cl}^{-}\right] /\left[\mathrm{OH}^{-}\right]$ratio in the solution is high, and $\sigma_{\mathrm{Ca}^{2+}}$ is large. Fig. 2 shows this not to be the case, which excludes $\mathrm{Cl}^{-}$adsorption as a significant contribution to the number of negative charges near the solid. At $\left[\mathrm{CaCl}_{2}\right]$
$=2 \cdot 10^{-4} M$, where the surface carries a negative charge, specific adsorption of $\mathrm{Cl}^{-}$is absent as evidenced by experiments in which $\left[\mathrm{Cl}^{-}\right]$ was measured before $\left(3.85 \times 10^{-4} M\right)$ and after $S / L$ contact $\left(4.02 \times 10^{-4} M\right.$ ) (duration of $S / L$ contact : $150 \mathrm{~min}$ ). To close the charge gap, a decrease in concentration to $2.5 \times 10^{-4}$ $M$ would have been necessary, which lies beyond the error in the $\mathrm{Cl}^{-}$concentrations determined $( \pm 0.3 \%)$. It should be remembered that specific adsorption of $\mathrm{Cl}^{-}$is absent on $\mathrm{SiO}_{2}$ (10), $\mathrm{TiO}_{2}$ (11), and $\mathrm{Fe}_{2} \mathrm{O}_{3}$ (12), and that electrokinetic data indicate absence of specific adsorption of $\mathrm{Cl}^{-}$on anorthite (2).

The lack of negative charges near or on the surface can be accounted for by desorption of positive network fragments. As such, $\mathrm{Al}^{3+}$ and $\mathrm{AlO}^{+}$can be considered. In the anorthite structure, $\mathrm{AlO}_{4}$ tetrahedra alternate with $\mathrm{SiO}_{4}$ tetrahedra (see Fig. 3), and from bond strength considerations a $\mathrm{Al}-\mathrm{O}-\mathrm{Si}$ bond is expected to have a greater chance of being broken at the $\mathrm{Al}-\mathrm{O}$ bond than at the $\mathrm{O}-\mathrm{Si}$ bond. Thus, the original surface will contain more $\mathrm{Al}^{3+}$ than $\mathrm{Si}^{4+}$ directly exposed without being covered by oxygen or hydroxyl ions. On contact with the solution, when $\mathrm{Al}^{3+}$ and $\mathrm{AlO}^{+}$pass in to the solution in excess (more than equivalent amounts towards $\mathrm{SiO}_{4}{ }^{4-}$ ), the surface will be left with a negative charge. The effect remains unaltered when the $\mathrm{Al}^{3+}$ and $\mathrm{AlO}^{+}$ions, once they have left the solid, undergo reactions with $\mathrm{OH}^{-}$ forming aluminate ions, as long as the analytical procedure employed for $\mathrm{OH}^{-}$determination does not distinguish between $\mathrm{OH}^{-}$and aluminate ions (as was the case here, since $\mathrm{OH}^{-}$titration was carried out to $\mathrm{pH} 5$ ).

After $150 \mathrm{~min}$ of $S / L$ contact with a $0.01 \mathrm{~N}$ $\mathrm{NaOH}, 2 \times 10^{-4} \quad M \mathrm{CaCl}_{2}$ solution 3.71 $\mu$ mole $\mathrm{m}^{-2} \mathrm{Al}$ had passed into the solution. This amount can account for the charge deficiency if $22 \%$ pass into the solution as $\mathrm{Al}^{3+}$ and the remainder as $\mathrm{AlO}^{+}$, if no $\mathrm{SiO}_{4}^{4-}$ goes into solution [concerning the latter assumption, see Smirnova's (13) and Ilers (14) data]. The difference with the $\alpha$ - $\mathrm{CaSiO}_{3}$ case should be clear, where dissolution of $\mathrm{Si}_{3} \mathrm{O}_{9}{ }^{6-}$ anions would expose $\mathrm{Ca}^{2+}$ ions to a solution poor in $\mathrm{Ca}^{2+}$. In 


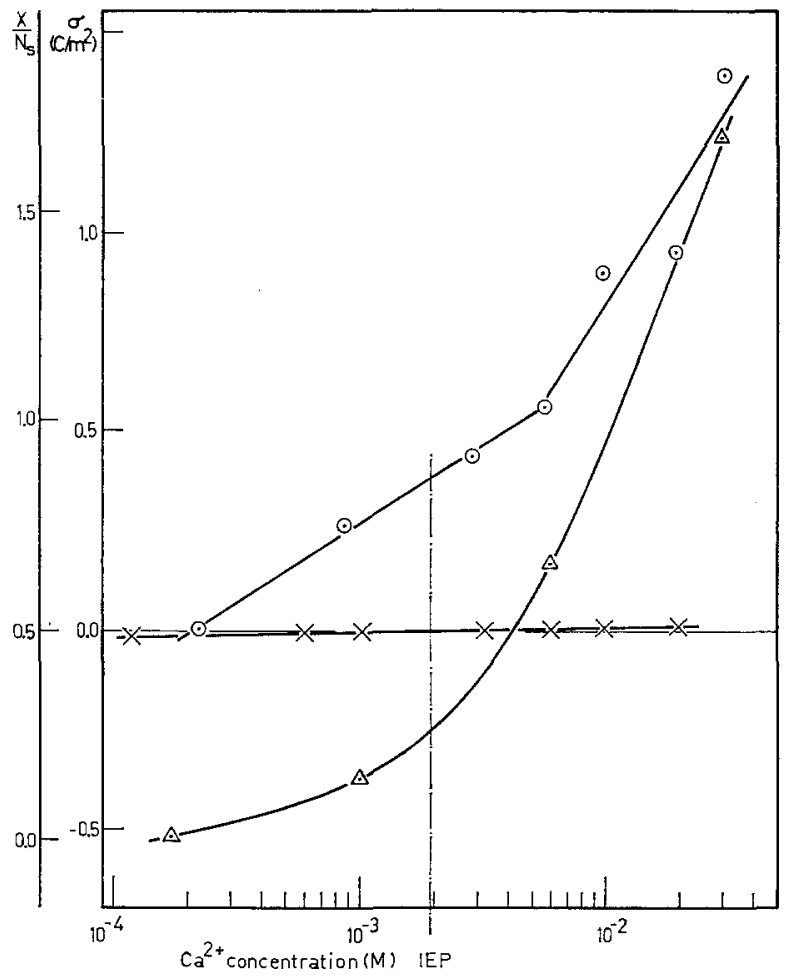

FIG. 2. Charges on $\mathrm{CaAl}_{2} \mathrm{Si}_{2} \mathrm{O}_{8} . \odot, \sigma_{\mathrm{Ca}} ; \triangle,-\sigma_{\mathrm{OH}} ; X, \sigma_{\mathrm{sI} \mathrm{pl}}$.

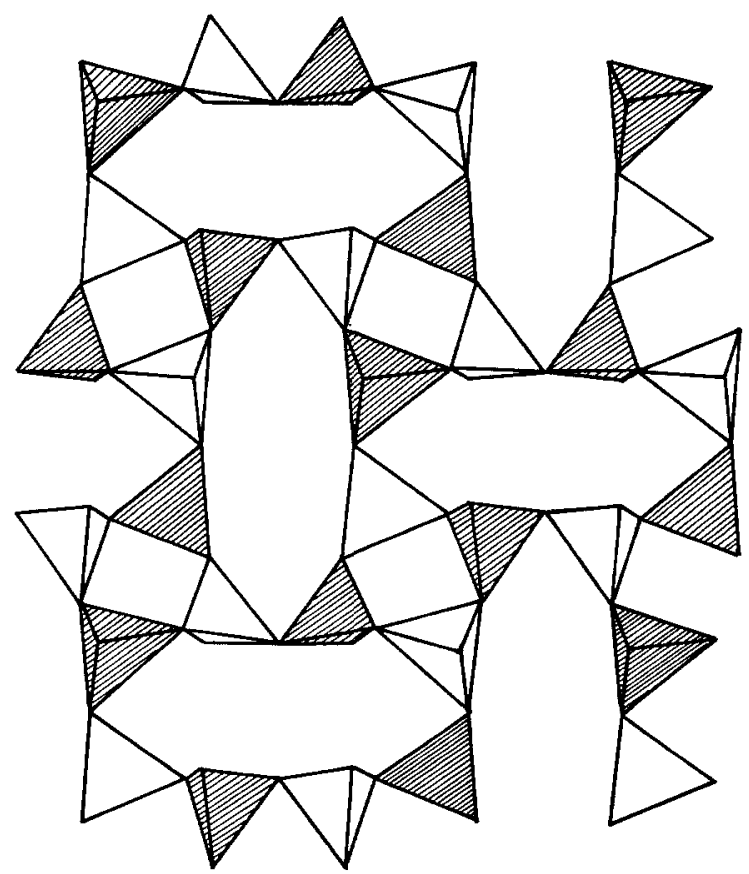

FIG. 3. Part of the anorthite network. Shaded tetrahedra, $\mathrm{AlO}_{4}$; blank tetrahedra, $\mathrm{SiO}_{4} . \mathrm{Ca}^{2+}$ ions are omitted. For clarity, only one layer of the continuous three-dimensional network is shown. 
TABLE II

Tracer Ad and Desorption of $\mathrm{Ca}^{2+}$ oN $\mathrm{CaAl}_{2} \mathrm{Si}_{2} \mathrm{O}_{8} \mathrm{IN} 0.01 \mathrm{~N} \mathrm{NaOH}$

\begin{tabular}{|c|c|c|c|c|c|}
\hline $\begin{array}{c}{\left[\mathrm{CaCl}_{2}\right]} \\
\text { after } \\
\text { adsorption } \\
\left(10^{-3} M\right)\end{array}$ & $\begin{array}{c}\text { Time } \\
\text { of } S / L \\
\text { contact } \\
\text { (minutes) }\end{array}$ & $K_{a}$ & $\begin{array}{r}K_{a} * \\
\text { (umole }\end{array}$ & ${ }_{n \rightarrow 2} H_{a}$ & $g$ \\
\hline 5.769 & 15 & 3.12 & 10.3 & 4.74 & 0.27 \\
\hline 5.748 & 45 & 3.48 & 5.0 & 5.18 & 0.29 \\
\hline 5.729 & 150 & 2.90 & 5.2 & 4.96 & 0.44 \\
\hline 5.656 & 300 & 3.52 & 5.3 & 4.61 & 0.52 \\
\hline 5.387 & 1440 & 8.30 & 26.1 & 4.24 & 0.67 \\
\hline 0.222 & 150 & 0.02 & 4.2 & -0.16 & 0.56 \\
\hline 0.871 & 150 & 1.36 & 2.7 & 0.71 & 0.43 \\
\hline 2.843 & 150 & 2.27 & 5.1 & 2.64 & 0.32 \\
\hline 5.729 & 150 & 2.90 & 5.2 & 4.96 & 0.44 \\
\hline 9.700 & 150 & 4.65 & 7.7 & 5.60 & 0.50 \\
\hline 19.686 & 150 & 4.92 & 10.1 & 6.12 & 0.31 \\
\hline 30.698 & 150 & 7.21 & 9.5 & 6.27 & 0.28 \\
\hline
\end{tabular}

$K_{a}$ and $K_{a}{ }^{*}$ have the same meaning as in Table $\mathrm{I}$.

$H_{a}=$ amount of $\mathrm{Ca}^{2+}$ adsorbed during alcohol treatment.

$g=$ fraction of the amount of ${ }^{45} \mathrm{Ca}^{2+}$ present in the solid after adsorption + alcohol treatment, which cannot be removed on desorption. (Desorption time: $30 \mathrm{~min}$.).

the anorthite case, part of the network remains on dissolution of $\mathrm{Al}^{3+}$ and $\mathrm{AlO}^{+}$.

Table II surveys data for the comparison of total adsorption and net adsorption. At $\left[\mathrm{CaCl}_{2}\right]=5.7 \times 10^{-3} M$, the net amount of $\mathrm{Ca}^{2+}$ adsorbed $\left(K_{a}\right)$ and the total amount of $\mathrm{Ca}^{2+}$ adsorbed $\left(K_{a}^{*}\right)$ are, with the exception of the 15-min contact-time experiment, reasonably constant up to about $5 \mathrm{hr}$, but both increase ultimately. If $\mathrm{CO}_{2}$ penetrating into the system, causing $\mathrm{CaCO}_{3}$ precipitation, would be responsible for the final increase, $K_{a}{ }^{*}-K_{a}$ should be equal to that found in experiments of shorter duration. Although the data are rather scarce, the final increase of $K_{a}{ }^{*}-K_{a}$ is distinct; it indicates a process involving dissolution of part of the solid and precipitation of hydrates. At higher $\left[\mathrm{CaCl}_{2}\right]$ concentrations, the adsorption data indicate a similar process even after short times $(2.5 \mathrm{hr})$. On the other hand, the difference in electrokinetic properties between $\mathrm{CaAl}_{2} \mathrm{Si}_{2} \mathrm{O}_{8}$ samples of varying degrees of surface disorder (2) indicates the absence of significant hydrate formation after short times at lower $\mathrm{CaCl}_{2}$.

The fraction of ${ }^{45} \mathrm{Ca}^{2+}$ present in the solid after adsorption that is not recovered on desorption, tends to increase with increasing $S / L$ contact time, and to decrease with increasing $\left[\mathrm{CaCl}_{2}\right]$. The former effect can be understood as indicating hydrate formation, the interpretation of the latter is not clear. It should be kept in mind that the amount of ${ }^{45} \mathrm{Ca}^{2+}$ present in the solid is determined to a large extent by the amount adsorbed during alcohol treatment ( $H_{a}$ in Table II), which does not change significantly with $S / L$ contact time, but increases with increasing $\left[\mathrm{CaCl}_{2}\right]$.

\section{DISCUSSION}

Fig. 1 indicates absence of multilayered precipitation of $\mathrm{Ca}(\mathrm{OH})_{2}$ on $\alpha-\mathrm{CaSiO}_{3}$. The adsorption of $\mathrm{Ca}^{2+}$ onto the surface shows a tendency towards saturation at higher $\left[\mathrm{CaCl}_{2}\right]$, a multilayered $\mathrm{Ca}(\mathrm{OH})_{2}$ precipitation should increase indefinitively as soon as a certain $\left[\mathrm{CaCl}_{2}\right]$ is surpassed. Similarly, from Fig. 2 we see the absence of a surface coverage by multilayered $\mathrm{Ca}(\mathrm{OH})_{2}$ for anorthite; although saturation is not observed here, and the amount of $\mathrm{Ca}^{2+}$ adsorbed surpasses the amount that can be accommodated in the first crystal layer, the $\mathrm{Ca}^{2+}$ adsorption increases in much too gradual a way for increasing $\left[\mathrm{CaCl}_{2}\right]$ for $\mathrm{Ca}(\mathrm{OH})_{2}$ precipitation to be acceptable.

On the other hand, the data indicate a mutual stimulation of $\mathrm{Ca}^{2+}$ and $\mathrm{OH}^{-}$adsorption for $\alpha-\mathrm{CaSiO}_{3}$. That $\mathrm{OH}^{-}$adsorption is stimulated by $\mathrm{Ca}^{2+}$ adsorption follows directly from the increasing $\mathrm{OH}^{-}$adsorption with increasing $\left[\mathrm{CaCl}_{2}\right] ;\left[\mathrm{OH}^{-}\right]$is constant, and the activity coefficients (at least those of electroneutral combinations of cations and anions) decrease in the region concerned with increasing electrolyte concentrations (15).

The stimulation of $\mathrm{Ca}^{2+}$ adsorption by increasing $\mathrm{OH}^{-}$adsorption follows from a quantitative consideration. If there is equilibrium between adsorbed $\mathrm{Ca}^{2+}$ and $\mathrm{Ca}^{2+}$ in solution, the electrochemical potential of these 
species must be equal. The surface will contain sites (type i), characterized by different standard chemical potentials of $\mathrm{Ca}^{2+}$ ions adsorbed unto them, $\mu_{i_{\text {ads }}}$; the electrochemical potential of a $\mathrm{Ca}^{2+}$ ion adsorbed on a site of type $i$ depends in addition on $\theta_{i}$, the degree of occupation of the sites of type $i$, and on $\psi_{i}$, the electrical potential at the site. We assume

$\mu_{i_{\mathrm{uds}}}=\mu_{i_{\mathrm{ads}}{ }^{o}}+R T \ln \theta_{i} /\left(1-\theta_{i}\right)+2 F \psi_{i} \quad$ [1]

in which the $\theta_{i}$ dependency is taken into account in the usual way (16). $\mu_{i_{\text {als }}}{ }^{o}$ will depend on the adsorption energy of $\mathrm{Ca}^{2+}$ ions onto the site concerned, which includes energy terms due to differences in degree of hydration of $\mathrm{Ca}^{2+}$ ions when adsorbed and when in solution.

It is taken to be independent of the degree of occupation of neighboring sites; the influence of the latter is taken account of through $\psi_{i}$.

If the electrical potential in the bulk solution is taken to be 0 , in accordance with the usual practice in colloid chemistry (17), we have

$$
\begin{aligned}
\mu_{i_{\mathrm{ads}}} o & +R T \ln \theta_{i} /\left(1-\theta_{i}\right)+2 F \psi_{i} \\
& =\mu_{\mathrm{Ca}}+R T \ln \gamma_{\mathrm{Ca}} m_{\mathrm{Ca}}
\end{aligned}
$$

where $\gamma_{\mathrm{Ca}}$ is the activity coefficient of $\mathrm{Ca}^{2+}$ in the solution. For convenience, the charge on the $\mathrm{Ca}^{2+}$ and indices $T, p$ constant are omitted in the following, where possible. Solvatation effects $(17-19)$ are considered to be only slightly dependent on $\psi_{i}$ and therefore included in $\mu_{i_{\text {ads }}}{ }^{o}$. On differentiation at constant $T$ and $p$, we obtain

$$
\begin{aligned}
\frac{d \theta_{i}}{\theta_{i}\left(1-\theta_{i}\right)}= & d \ln \gamma_{\mathrm{Ca}}+d \ln m_{\mathrm{Ca}}-\frac{2 F}{R T} d \psi_{i}[3] \\
\frac{\partial \theta_{i}}{\partial \ln m_{\mathrm{Ca}}}= & {\left[1+\frac{\partial \ln \gamma_{\mathrm{Ca}}}{\partial \ln m_{\mathrm{Ca}}}\right.} \\
& \left.-\frac{2 F}{R T} \frac{\partial \psi_{i}}{\partial \ln m_{\mathrm{Ca}}}\right] \theta_{i}\left(1-\theta_{i}\right) \quad[4]
\end{aligned}
$$

The experimentally accessible quantity is

$$
\frac{\partial X}{\partial \ln m_{\mathrm{Ca}}}=\sum_{i} N_{i} \frac{\partial \theta_{i}}{\partial \ln m_{\mathrm{Ca}}}
$$

where $N_{i}=$ number of sites of type $i$ per unit area; and $X=$ number of $\mathrm{Ca}^{2+}$ ions present at the surface per unit area.

Combining Eqs. [4] and [5], we obtain

$$
\begin{array}{r}
\frac{\partial X}{\partial \ln m_{\mathrm{Ca}}}=\left[1+\frac{\partial \ln \gamma_{\mathrm{Ca}}}{\partial \ln m_{\mathrm{Ca}}}-\frac{2 F}{R T} \overline{\frac{\partial \psi}{\partial \ln m_{\mathrm{Ca}}}}\right] \\
\times \sum_{i} N_{i} \theta_{i}\left(1-\theta_{i}\right)
\end{array}
$$

where an average potential increase of all adsorption sites has been introduced, defined by

$$
\begin{array}{r}
\left.\frac{\partial \psi}{\partial \ln m_{\mathrm{Ca}}}=\sum_{i}\left(\partial \psi_{i} / \partial \ln m_{\mathrm{Ca}}\right) \theta_{i}\left(1-\theta_{i}\right) N_{i}\right) \\
\times\left(\sum_{i} \theta_{i}\left(1-\theta_{i}\right) N_{i}\right)
\end{array}
$$

It follows from this definition that $\overline{\partial \psi / \partial \ln m_{\mathrm{Ca}}}$ is determined primarily by those sites where $\theta_{i}$ is near $\frac{1}{2}$. However, when $\psi_{i}$ takes account of the degree of occupation of neighboring sites and a random distribution of sites of different types on the surface is assumed, no significant difference between $\overline{\partial \psi / \partial \ln m_{\mathrm{Ca}}}$ as defined by [7] and an unweighted average is expected. Thus, from [6]:

$$
\begin{gathered}
\frac{\partial \psi}{\partial \log m_{\mathrm{Ca}}}=2.303 \frac{R T}{2 F}\left[1+\left(\partial \log \mathrm{Ca} / \partial \log m_{\mathrm{Ca}}\right)\right. \\
\left.-\left(\partial X / \partial \log m_{\mathrm{Ca}}\right) / 2.303 \sum_{i} \theta_{i}\left(1-\theta_{i}\right) N_{i}\right]
\end{gathered}
$$

Since $0 \leqslant \theta_{i} \leqslant 1,0 \leqslant \theta_{i}\left(1-\theta_{i}\right) \leqslant \frac{1}{4}$, Therefore

$$
\sum_{i} \theta_{i}\left(1-\theta_{i}\right) N_{i} \leqslant \frac{1}{4} \sum_{i} N_{i}=\frac{1}{4} N_{s}
$$

where $N_{s}=$ total number of sites per unit area.

For $\alpha-\mathrm{CaSiO}_{3}$, we estimate $N_{s}=6.1 \mathrm{~nm}^{-2}$ (see Results section). From Fig. 1, we read for $\partial X / \partial \log m_{\mathrm{Ca}}$ in the vicinity of the IEP: $15.4 \times 10^{17} \mathrm{~m}^{-2}$ per decade (which means on 
increasing $\log m_{\mathrm{Ca}}$ by 1). For $\partial \log \gamma_{\mathrm{Ca}} /$ $\partial \log m_{\mathrm{Ca}}$ we fill in the Debye-Hückel value for the medium concerned (20), -0.0913 . Thus, from [8]:

$\overline{\partial \psi / \partial \log m_{\mathrm{Ca}}} \leqslant 14.0 \mathrm{mV}$ per decade.

This appears, at first sight, to be at variance with

$\partial \zeta / \partial \log m_{\mathrm{Ca}}=26.0 \mathrm{mV}$ per decade (2),

because this would imply a negative capacity of the Stern layer. The discrepancy cannot be due to an error in the estimated value of $N_{s}$, since $N_{s}$ should have much higher values in order to close the gap between [10] and [11]; these values would be acceptable only if a multilayered $\mathrm{Ca}(\mathrm{OH})_{2}$ or calcium silicate hydrate with $\mathrm{CaO} / \mathrm{SiO}_{2}$ molar ratio higher than 1 are formed on the $\mathrm{CaSiO}_{3}$.

Since arguments have been put forward against these alternatives, the discrepancy between $\overline{\partial \psi / \partial \log m_{\mathrm{Ca}}}$ and $\partial \zeta / \partial \log m_{\mathrm{Ca}}$ is ascribed to the systematic difference between the average potential at the $\mathrm{Ca}^{2+}$ adsorption sites, and the average potential of the whole wall. The former is influenced by ions adsorbed on neighboring sites. These will, for a $\mathrm{Ca}^{2+}$ site, be occupied preferentially by $\mathrm{OH}^{-}$ions (or by $\mathrm{SiO}^{-}$originating on dissociation of surface $\mathrm{SiO}_{4}$ groups). Thus, $\mathrm{OH}^{-}$adsorption stimulates $\mathrm{Ca}^{2+}$ adsorption on $\alpha-\mathrm{CaSiO}_{3}$.

Similarly, on $\mathrm{CaAl}_{2} \mathrm{Si}_{2} \mathrm{O}_{8}, \overline{\partial \psi / \partial \log m_{\mathrm{Ca}}}$ for $\mathrm{Ca}^{2+}$ sites is calculated to be $\leqslant 8.0 \mathrm{mV}$ per decade. In this calculation, $N_{s}$ for anorthite is taken as $3.3 \mathrm{~nm}^{-2}$ (which is the value estimated from the dimensions of the unit cell), since in the vicinity of the IEP no adsorption of more $\mathrm{Ca}^{2+}$ than can be accommodated in the first layer is apparent; therefore, in view of the difference in IEP between crystalline and vitreous $\mathrm{CaAl}_{2} \mathrm{Si}_{2} \mathrm{O}_{8}$ (2), essentially unchanged distances between $\mathrm{Ca}^{2+}$ adsorption sites on the surface are assumed. Anyhow, for $\mathrm{CaAl}_{2}$ $\mathrm{Si}_{2} \mathrm{O}_{8} \partial \zeta / \partial \log m_{\mathrm{Ca}}$ surpasses even the change in "Nernst" potential which should be valid for the wall potential if there would be no influence other than the average wall potential, on the electrochemical potential of an adsorbed $\mathrm{Ca}^{2+}$ ion. Thus, such a simple model is not applicable in the case at hand.

The order of magnitude of the effect of mutual stimulation can be calculated, for $\alpha-\mathrm{CaSiO}_{3}$, from the following model. Every $\mathrm{Ca}^{2+}$ site is granted a square $0.404 \times 0.404$ $\mathrm{nm}^{2}$, using the same model as was used for the estimation of $N_{s}$. The $\mathrm{Ca}^{2+}$ ion is thought to occupy the center of this square. The corners of these squares are thought to be available for $\mathrm{OH}^{-}$adsorption. Additional $\mathrm{OH}^{-}$can be situated on the top of a $\mathrm{Ca}^{2+}$ ion or below (the latter, for instance, as $\mathrm{SiO}^{-}$group). The distances between $\mathrm{Ca}^{2+}$ and $\mathrm{OH}^{-}$ions in the corners of the squares are $0.29 \mathrm{~nm}$, and between $\mathrm{Ca}^{2+}$ and $\mathrm{OH}^{-}$on top of that $\mathrm{Ca}^{2+}$ it is $0.24 \mathrm{~nm}$. This model is both consistent with the numbers of $\mathrm{Ca}^{2+}$ and $\mathrm{OH}^{-}$sites required by the data and with sterical requirements.

The contributions to the potential of a $\mathrm{Ca}^{2+}$ ion from ions, $\mathrm{Ca}^{2+}$ as well as $\mathrm{OH}^{-}$, are then summarized, assuming that the relative dielectric constant near the solid is 6 , and assuming all sites to be occupied $\left(X / N_{s}=1\right)$, until the potential does no more change on including additional charges farther away. This gives $\Delta \psi=-0.53 \mathrm{~V}$. Thus,

$$
\frac{\partial \psi}{\partial\left(X / N_{s}\right)}=-0.53 \mathrm{~V} \text { for a } \mathrm{Ca}^{2+} \text { site }
$$

and since $\partial\left(X / N_{8}\right) / \partial \log m_{\mathrm{Ca}}=0.25$ in the vicinity of the IEP (see Fig. 1), we get $\partial \psi /$ $\partial \log m_{\mathrm{Ca}}=-0.13 \mathrm{~V}$ per decade. Similarly, for an $\mathrm{OH}^{-}$site, $\partial \psi / \partial \log m_{\mathrm{C} \Omega}=0.67 \mathrm{~V}$ per decade.

There is a certain resemblance of the model of "mutual stimulation" of ions adsorbed on adjacent sites, which has been developed here, and Levine's "discrete ion" effect (21). However, there are fundamental differences: Levine calculated the influence of a random ionic environment in the adsorbed layer, whereas here a preferentially ordered surrounding of adsorbed $\mathrm{Ca}^{2+}$ by adsorbed $\mathrm{OH}^{-}$is assumed, as is shown to be more realistic in our case by the fact that $\sigma_{\mathrm{Ca}}$ is compensated chiefly by $\mathrm{OH}^{-}$ 
adsorption without $\mathrm{Cl}^{-}$entering into the picture. Moreover, if we were to treat $\mathrm{Ca}^{2+}$ adsorption in our systems according to Levine's model, we should have to consider all ions adsorbed, $\mathrm{Ca}^{2+}$ as well as $\mathrm{OH}^{-}$, as situated in one "inner Helmholtz plane" which would raise questions, however, about why $\mathrm{Ca}^{2+}$ ions are adsorbed at all to an amount leading to charge reversal of the surface.

A description of the simultaneous increase of $\mathrm{Ca}^{2+}$ and $\mathrm{OH}^{-}$adsorption with increasing $\mathrm{CaCl}_{2}$ as surface precipitation of $\mathrm{Ca}(\mathrm{OH})_{2}$ (19) is avoided in this paper. The use of this term would imply that the phenomena are determined by a mutual interaction between $\mathrm{Ca}^{2+}$ and $\mathrm{OH}^{-}$essentially similar to that in solid $\mathrm{Ca}(\mathrm{OH})_{2}$, only stimulated by an electric field near the phase boundary. If this would be correct, the solubility product of $\mathrm{Ca}(\mathrm{OH})_{2}$ should be strongly dependent on whether conditions correspond to the point of zero charge of $\mathrm{Ca}(\mathrm{OH})_{2}$, or not, since this determinates the field strength near the $\mathrm{Ca}(\mathrm{OH})_{2} /$ solution boundary. This has until now not been reported. Description of the phenomena as mutual stimulation of $\mathrm{Ca}^{2+}$ and $\mathrm{OH}^{-}$ adsorption, on the other hand, implies that adsorption is in all determined to an important degree by the solid silicate surface. This is considered to be more realistic in the present case; it should be remembered that the term $\mathrm{OH}^{-}$adsorption includes bere dissociation of surface $\mathrm{SiOH}$ groups.

Tadros and Lyklema's model $(10,22,23)$ of one ionic species as primary charging unit $\left(\mathrm{OH}^{-}\right.$in the case of $\left.\mathrm{SiO}_{2}\right)$, whose charge is compensated almost completely by counter ions simultaneously adsorbed (cations in the case of $\mathrm{SiO}_{2}$ ) excludes superequivalent adsorption of the counter ions; moreover, the charge brought to the surface by the primary charging ion according to this model should be independent of the amount of following ions adsorbed. Since both conclusions do not apply in the cases of $\alpha-\mathrm{CaSiO}_{3}$ and $\mathrm{CaAl}_{2} \mathrm{Si}_{2} \mathrm{O}_{8}$ (see the charge reversal observed, and Figs. 1 and 2), the model of mutual stimulation of ion adsorption is here thought to be more realistic.

\section{ACKNOWLEDGMENT}

The authors wish to thank Mrs. Lacroix-Hovens for carrying out part of the analyses and Dr. W. Smit for many discussions. The first author wishes to thank the Netherlands Organization for Applied Scientific Research (TNO) for financial support.

\section{REFERENCES}

1. Stein, H. N., J. Colloid Interface Sci. 28, 203 (1968).

2. Siskens, C. A. M., Stein, H. N., And Steveis, J. M., J. Colloid Interface Sci. 52, (1975).

3. BIRKs, J. B., "The Theory and Practice of Scintillation Counting." Pergamon Press, Oxford, 1964.

4. Gran, G., The Analyst 77, 661 (1952).

5. Amos, M. D., and Tromas, P. E., Anal. Chim. Acta 32, 139 (1965).

6. Willis, B. J., Appl. Optics 7, 1295 (1968).

7. Aveyard, R., and Haydon, D. A., "An Introduction to the Principles of Surface Chemistry," pp. 41-42. Cambridge University Press, New York, 1973.

8. Laddelout, H., Bull. Groupe Francaise Argiles 9, 61 (1957).

9. SMTT, W., AND Stein, H. N., to be published.

10. Tadros, T. F., aNd Lykiema, J., J. Electroanal. Chem. 17, 267 (1968).

11. Bérubé, Y. G., AND DE Bruyn, P. L., J. Colloid Interface Sci. 27, 305 (1968).

12. Breeuwsma, A., and Lyklema, J., $J$. Colloid Interface Sc. 43, 437 (1973).

13. Smirnova, Mi F., Dushina, A. P., and AlesкovsKI, V.. B., Izv. Akad. Nauk. SSSR Neorg. Mater. 2, 284 (1966).

14. Iler, R. K., J. Colloid Interface Sci. 43, 399 (1973).

15. Robinson, R. A., and Stokes, R. H., "Electrolyte Solutions," Butterworths, London, 1955.

16. Fowler, R. H., AND GUGGenheIm, E. A., "Statistical Thermodynamics," p. 426. Cambridge University Press, New York, 1939.

17. Wiese, G. R., James, R. O., and Healy, T. W., Disc. Faraday Soc. 52, 302 (1971).

18. Levine, S., Disc. Faraday Soc. 52, 320 (1971).

19. James, R. O., and Heaty, T. W., J. Colloid Interface Sci. 40, 53, 55 (1972).

20. KortüM, G., "Lehrbuch der Elektrochemie," 3 Aufl. Verlag Chemie, Weinheim, 1962.

21. Levine, S., J. Colloid Interface Sci. 37, 619 (1971).

22. LikLema, J., J. Electroanal. Chem. 18, 341 (1968).

23. Tadros, T. F., and Lyklema, J., $J$. Electroanal. Chem. 22, 1 (1969). 